\title{
CORRIGENDUM
}

\section{Disparity of histone deacetylase inhibition on repair of radiation-induced DNA damage on euchromatin and constitutive heterochromatin compartments}

TC Karagiannis, KN Harikrishnan and A El-Osta

Oncogene (2007) 26, 5028; doi:10.1038/sj.onc.1210554

\section{Correction to:}

Oncogene (2007) 26, 3963-3971. doi:10.1038/sj.onc.1210174; published online 8 January 2007
Since the publication of the above article, the authors have identified an error in the author list, the name of the second author was incorrectly presented. The corrected author list is shown above. 